\title{
Notas
}

\section{Alternância e política exterior no México: uma mensagem do Presidente}

\author{
VICENTE FOX QUESADA
}

A política exterior mexicana atravessa atualmente um período de renovação estreitamente vinculado ao processo de transição em que vive o país. O México mudou e, conseqüentemente, era necessário pôr em dia seus vínculos com outros povos, assim como seu papel nos fóruns internacionais. Essa atualização de nossas relações com outras nações está ligada ao processo de consolidação da democracia em nosso país. A atual política exterior mexicana é o reflexo externo do mandato de mudança, expressado nas urnas em 2 de julho de 2000 e, ao mesmo tempo, um poderoso instrumento para alavancar a transição democrática no país.

Ao assumir o governo, encontramos, como acontece em todo processo de alternância, após um longo monopólio de poder, um legado complexo de avanços e retrocessos, bem como um desafio difícil de continuidade e mudança. Em matéria de política exterior, a diplomacia praticada durante os setenta anos de governo monopartidário merece um julgamento matizado. Existiram períodos de passividade, mas também momentos ativos e brilhantes, como a manutenção das relações diplomáticas com a República Espanhola, a rejeição ao isolamento de Cuba, a ruptura das relações com o regime de Pinochet no Chile e o repúdio ao apartheid na África do Sul. Houve também gestos de vanguarda, como o papel desempenhado no conflito de El Salvador e, posteriormente, no processo de Contadora.

Contudo também devemos reconhecer que todos esses esforços foram se paralisando paulatinamente, como resultado da incapacidade desse regime para reconhecer que o mundo tinha mudado. Primeiramente, o degelo bipolar foi para ele adverso, na medida em que as novas prioridades da agenda internacional centravam-se justamente nos pontos fracos da falta de democracia, transparência e direitos humanos no meu país. Isso provocou uma obnubilação e perda de liderança. Em segundo lugar, a rota escolhida nesse novo contexto internacional, a construção de um arcabouço de acordos de livre comércio, alargou as relações econômicas do México, mas tornou ainda mais evidente as limitações da democracia e do Estado de Direito no país. 
Hoje, as mudanças no México e no mundo indicam o que deve ser conservado e o que deve ser descartado dessa política exterior e, acima de tudo, o que é preciso criar para construirmos o nosso futuro. A política exterior do México deve continuar a proteger os interesses medulares da nossa nação, sua segurança nacional, a preservação de sua capacidade de manobra internacional, a estabilidade e a cooperação internacionais, o aproveitamento de nossos recursos naturais, de acordo com as necessidades e prioridades do país, o impulso para o desenvolvimento nacional integral sustentado e sustentável, e a capacidade soberana para assumir decisões, sem restrições, em benefício de interesses. Mas deve fazê-lo dentro das novas condições apresentadas pelo atual sistema internacional.

Foi por essas razões que a articulamos em torno de dois eixos principais: 0 primeiro consistiu em desenvolvermos uma atividade mais intensa nos fóruns multilaterais, e o segundo tentou aprofundar estrategicamente o nosso relacionamento com os Estados Unidos e o Canadá, na América do Norte. Ambos são parte essencial de nossa estratégia internacional e se complementam mutuamente.

Nos anos recentes, um novo sistema internacional vem sendo desenvolvido, o qual está orientado para o estabelecimento de normas e princípios de jurisdição universal, por cima da soberania nacional, em âmbitos da chamada Nova Agenda, como os direitos humanos e a democracia, as questões de gênero e discriminação, a proteção do meio ambiente e o combate ao crime organizado e à corrupção.

O México sempre lutou por um sistema internacional baseado no direito e nas suas regras e normas. O que atualmente mudou foi a natureza destas últimas e não o interesse do México em uma ordem internacional codificada. A construção de novas regras de convivência internacional deverá continuar, seja com a nossa participação ou sem ela. Não tenho dúvidas de que para o México convém desempenhar um papel ativo na sua definição, tanto pela nossa posição, como país ponte entre culturas e regiões, quanto pela sua tradição diplomática e pela legitimidade democrática do governo atual. Deve-se a isso o fato de estarmos participando ativamente em diversos fóruns para a construção dessa arquitetura internacional.

Esse novo ativismo mexicano já está dando frutos. Para começar, obtivemos o apoio da Comunidade das Nações para o nosso país ingressar como membro não permanente no Conselho de Segurança das Nações Unidas. Com essa mesma decisão, avançamos no cumprimento do nosso renovado compromisso com os direitos humanos. Por um lado, estamos harmonizando a legislação mexicana com o marco normativo internacional. Por outro, o México está usando sua voz e seu voto para promover esses direitos fundamentais no mundo inteiro.

Isso é confirmado pela nossa participação na Conferência de Durban contra o Racismo e a Discriminação, na qual promovemos a incorporação do reconhecimento pleno de todos os direitos dos povos indígenas e da positiva contribuição econômica e cultural dos migrantes para os países de destino. A 
votação sobre Cuba, na Comissão passada de Direitos Humanos da ONU, constitui claro exemplo da nossa congruência nesse tema, mas, da mesma forma, também é exemplificada pelos votos emitidos na situação dos direitos humanos na Palestina e na Chechênia, ou pela resolução promovida pelo México, para garantir o respeito aos direitos humanos na luta contra o terrorismo que, infelizmente, não prosperou nesta ocasião.

O México comprometeu-se ativamente na luta que se abre hoje contra o terrorismo internacional, e fazemos isso porque acreditamos que é um desafio fundamental para a segurança e o bem-estar da comunidade das nações, e também porque constitui uma ameaça contra os valores mais fundamentais de nossas sociedades. Contudo, essa luta terá de ser inteligente, paciente e integral. Seria paradoxal que, em nossos esforços para cortar os vasos comunicantes que alimentam o terrorismo, terminássemos vulnerabilizando os nossos princípios e as nossas normas de convivência internacional, que são, em última instância, o alvo de ataque desses grupos.

Também temos reafirmado a nossa vontade de impulsionar os valores democráticos no mundo. Um antecedente fundamental para o nosso trabalho foi a Cláusula Democrática negociada pelo regime anterior no Acordo Global entre o nosso país e a União Européia. Em setembro do ano passado, o México promoveu a subscrição da Carta Democrática Interamericana, por meio da qual as nações do hemisfério expressaram seu comprometimento com a democracia como forma de governo. A recente ruptura institucional na Venezuela pôs em xeque a firmeza das nossas convicções, e a liderança do México nesse âmbito foi um fator decisivo para o restabelecimento da ordem constitucional nesse país.

O novo ativismo do México também ficou credenciado na Conferência sobre Financiamento para o Desenvolvimento, realizada na cidade de Monterrey, na qual o nosso país assumiu o papel de liderança na configuração de um sistema internacional mais eqüitativo, que possa oferecer novas oportunidades às nações menos desenvolvidas. Juntamente com a Conferência de Johanesburgo, a Reunião Ministerial da Organização Mundial do Comércio, que será realizada no próximo ano no México, permitirá darmos continuidade ao importante trabalho iniciado na Reunião Ministerial da Organização Mundial do Comércio, em Doha, em prol de um desenvolvimento mais justo.

A ativa participação do México no âmbito multilateral também contribui para fortalecer nossas relações com outros países e regiões. Por isso uma das prioridades da nossa chancelaria ao longo dos meses passados foi a construção daquilo que, pela falta de um nome melhor, chamamos de "bilateralismo multilateral", isto é, a busca de convergências, principalmente com nações da Europa e da América Latina, nos temas da nova agenda. Implementamos esse enfoque particularmente com a Grã-Bretanha, a Espanha, a França e o Chile. Continuaremos fazendo o mesmo com outras nações, porque estamos convencidos de que é essa 
a melhor maneira de outorgar maior peso político às relações bilaterais do México com nações européias e latino-americanas.

Em especial, o México tem uma profunda vocação latino-americana, sustentada em valores culturais compartilhados e em uma história comum que nos aproxima e identifica. Estamos comprometidos com a integração e o processo político da unidade latino-americana. Por isso temos exercitado uma diplomacia ativa que impulsiona o diálogo em todos os âmbitos regionais. Queremos propiciar um papel de vanguarda por parte de nossa região em todos os temas da agenda internacional que são relevantes para nossas nações.

Um exemplo de destaque desta nova orientação é a iniciativa que o México lançou junto com os países da América Central para promover o desenvolvimento econômico sustentado e sustentável, mediante o Plano Puebla-Panamá, o qual responde a uma nova perspectiva integral de desenvolvimento socioeconômico regional. Outrossim, estamos promovendo uma aproximação com os países que integram a Comunidade do Caribe, que para o México constitui uma terceira fronteira de grande importância. Com este propósito, nosso país tem incrementado sua cooperação com as nações caribenhas e fez um chamado a superar os obstáculos que a falta de acordos sobre limites marítimos impõe, mediante a celebração de uma conferência sobre delimitação marítima.

Temos encorajado, outrossim, um diálogo de alto nível com as nações da América Latina, renovando e fortalecendo os mecanismos de ajuste político e complementação econômica, e atualizando os instrumentos jurídicos que regulam nossos intercâmbios comerciais e de cooperação. Em particular com os governos da Argentina, Brasil e Chile, estamos impulsionando uma relação especial que se consolide como eixo de ajuste político para temas da agenda mundial. Este novo impulso às nossas relações procura somar esforços para conseguir uma maior e mais eficaz influência no sistema internacional.

O segundo eixo da política exterior do México foi a construção de uma associação estratégica para a prosperidade com os Estados Unidos e com o Canadá, partindo de um relacionamento, já estreito, que descansa sobre o Tratado de Livre Comércio da América do Norte - NAFTA - e que é articulado em torno de uma visão integral de longo prazo e conceitualmente inovadora. A densidade e complexidade dos temas da nossa agenda bilateral com os Estados Unidos, conforme é normal que aconteça entre dois vizinhos e parceiros tão assimétricos, têm uma dimensão particular pela presença de amplas comunidades mexicanas assentadas nesse país, mais de 20 milhões de compatriotas. Nos últimos meses, conseguimos melhorar a situação de muitos mexicanos fixados nesse país, independentemente de sua situação migratória, por meio de esquemas que lhes permitiram o acesso aos sistemas educacionais e de saúde, bem como a documentos de identidade.

Isso tudo teve como resultado, no ano passado, um avanço conceitual extraordinário nas relações entre México e os Estados Unidos, particularmente no 
assunto migratório e na importância de se dirigir, paulatinamente, para a regularização da situação migratória dos nossos conterrâneos nos Estados Unidos, um número estimado entre três e quatro milhões de mexicanos. O nosso objetivo de longo prazo é estabelecermos com os Estados Unidos, e também com o Canadá, o nosso outro parceiro regional, um conjunto de vínculos e instituições similares àqueles criados pela União Européia, visando cobrir temas tão importantes para a futura prosperidade da América do Norte, como a liberdade de movimentação de capitais, bens, serviços e pessoas. Embora este seja um objetivo aparentemente difícil, estamos tentando assentar, de forma visionária, as bases do nosso relacionamento com um horizonte de vinte e cinco anos.

O novo padrão que desejamos instituir está inspirado no exemplo da União Européia, embora não se trate de uma cópia, mas de uma atualização desse processo. Não é a mesma coisa a integração entre nações soberanas em 1958, que no ano 2002; não é a mesma coisa formar uma comunidade com países que já contam com um grau de desenvolvimento relativamente homogêneo, que formá-la entre nações com enormes assimetrias; não é a mesma coisa estabelecer instituições comunitárias durante a Guerra Fria, que sob as exigências impostas pelos fatos de 11 de setembro do ano passado. E temos que enfrentar, da mesma forma, aquilo que eu me atreveria a chamar de preconceito anglo-saxão contra o estabelecimento de instituições supranacionais. Contudo, acredito que poderemos superar os obstáculos, com realismo, e construirmos uma comunidade mais próspera e segura para os nossos povos.

É por isso que meu governo vê na política exterior um instrumento para impulsionar e alavancar a mudança democrática no México. Onde antigamente o olhar externo era bloqueado, é hoje bem-vindo; onde antigamente olhava-se com receio a interação com o mundo externo, hoje ela é encorajada. Queremos buscar no exterior um arcabouço institucional para consolidarmos no interior do nosso país a plena observância do respeito aos direitos humanos, o aprofundamento da prática democrática e a transparência na vida pública. Assim, tanto o México que hoje impulsiona suas iniciativas nos fóruns multilaterais, quanto aquele que empreende um longo e fértil caminho de integração regional, é o México da alternância que desejava e deseja cada vez mais a maioria das mexicanas e mexicanos. E é esse o México da mudança, que tem a ambição de fazer de sua política exterior uma das chaves para o futuro bem sucedido do nosso país, assim como para a cooperação e a estabilidade em todo o nosso hemisfério. 